\title{
Cinderelas, bailarinas e a vida longa das galanterias
}

Cinderellas, ballerinas and the long life of gallantries

http://dx.doi.org/10.1590/1982-02672019v27e27

\author{
VÂNIA CARNEIRO DE CARVALHO' \\ https:/ / orcid.org/0000-0003-3840-8987 \\ Universidade de São Paulo / São Paulo, SP, Brasil
}

RESUMO: $\bigcirc$ artigo discute a constituição da identidade feminina associada à exibição do corpo. A sexualização da questão deixou esquecida uma matriz de longa tradição, a etiqueta aristocrática francesa do século XVIII. Uma das estratégias sociais de conservação desse repertório cenográfico se deu com a produção de esculturas representando cenas da aristocracia que ficaram conhecidas como fêtes galantes. Tais objetos estão associados a uma rede de representações que abrangem o balé clássico e os filmes e desenhos animados presentes no imaginário de crianças e adultos. ${ }^{2}$

PALAVRAS-CHAVE: Cultura material. Estudos de gênero. Porcelana Rebis. Fête Galante.

ABSTRACT: The article discusses the formation of feminine identity associated with body exposure. The sexualization of this issue has left a long lasting matrix behind - the aristocratic French etiquette of the $18^{\text {th }}$ century. One of the social conservation strategies of this scenographic repertoire may be found in the production of sculptures that represented aristocratic scenes, which became known as fêtes galantes. These objects are associated with a network of representations as wide as the classical ballet, films and animations present in adults' and children's imagery.
1. Docente do Museu Paulista da Universidade de São Paulo. Mestre e doutora pela mesma Universidade. Atua, desde 1990, como curadora de suas coleções e pesquisadora de História com ênfase em cultura material e espaço doméstico. E-mail: <vcarvalh@usp.br>

2. A pesquisa tem o apoio de agência de financiamento de pesquisa, processo $n$. 2017/07366-1, Fundação de Amparo à Pesquisa do Estado de São Paulo (Fapesp).

KEY-WORDS: Material culture. Gender studies. Rebis porcelain. Fête Galante. 
3. Este texto foi originalmente apresentado, em versão mais sucinta, comotrabalho encomendado pelo GTHistória da Educação, coordenado pela Profa. Dra. Maria Helena Câmara Bastos/PUC-RS na 37a Reunião Nacional da Associação Nacional de Pósgraduação e Pesquisa em Educação (Anped) em 5/10/2015.

4. Cf. Bernardi (2015).

5. A ideia de convergência é de Michel Foucault (1977).

6. A relação de causa e efeito aplicada aos fenômenos sociais faz com que parte dos agentes envolvidos, aqueles que são o "efeito", seja compreendida de maneira reducionista e passiva. A noção é questionada, entre outros, por Latour (2012).

7. LGBTQIA+ é a sigla usada para representar a diversidade de orientações sexuais e identidades de gênero, indicando: Lésbicas, Gays, Bissexuais, Transexuais ou Transgêneros, Queer, Intersexo, Assexuais e Mais formas possíveis não incluídas nas demais categorias.

8. Cf. Miller (2004, p. 30810) e Cerri; Silva (2013).

9. Cf. Offen; Pierson; Rendall (1991), Colomina (1992), Kirkham (1996), Grazia; Furlough (1996), Lima (1997), Ardener (1997), Montgomery (1998), Sharp (2004) e Carvalho; Lima (2005).

10. Emmanuel Le Roy Ladurie (2011, p.247-267) propôs identificar nos movimentos sociais de longa duração o momento de mudança, o a c o n t e c i m e $\mathrm{nto}$ desencadeador do processo.
A colunista da Folha de S.Paulo Tati Bernardi publicou em junho de 2015 uma pequena reflexão sobre a exposição do corpo feminino intitulada "Não quero transar". ${ }^{3}$ Nesse texto, ela defende o direito da mulher de sair de casa sem se preocupar com o modo como está vestida, maquiada ou penteada. Ela se referia à expectativa masculina de encontrar as mulheres sempre preparadas para a sedução. Provoca-nos Bernardi: em vez de shortinho curto e justo combinando com a meia arrastão, por que não se pode sair à rua com aquele moleton tamanho $G G$ furado? Ela acrescenta: "Sempre ouvi que eu deveria ser menos engraçada e mais feminina. Que eu deveria falar menos palavrões e sorrir mais. Que eu deveria fazer menos caretas e concordar mais." 4

Apesar das conquistas feministas já sedimentadas, os pais de mulheres jovens ou adolescentes sabem que o assunto, se colocado num diapasão mais amplo, é relevante e muito atual. No entanto, acredito que o tema da exibição do corpo feminino não se reduz à expectativa de uma atitude de "prontidão" sedutora que a mulher deveria assumir perante o homem. Não se trata apenas de sexo ou de sua idealização. Nesse caso, para entendermos o fenômeno, parece necessário buscar as trajetórias de diferentes processos que, apesar de autônomos, convergiram ${ }^{5}$ e passaram a viver uma espécie de simbiose. Trata-se de processos que não têm uma relação de causa e efeito linear, ${ }^{b}$ mas são resultantes de um acúmulo de hábitos e de significações que, ao conviverem, retroalimentam-se, metamorfoseam-se, adaptam-se e, com isso, prolongam sua vida social.

É fato que nossa sociedade conhece hoje uma variedade de orientações sexuais e suas correspondentes manifestações identitárias que superam a tradicional dicotomia entre masculino e feminino. Uma parcela significativa do repertório material e performático dos grupos LGBTQIA+ ${ }^{7}$ inclui recombinações e ressignificações do repertório tradicionalmente criado para os heterossexuais, o que já bastaria como incentivo ao seu estudo. No entanto, neste artigo trato de questão que me parece igualmente relevante para chegar a uma compreensão consistente dos fenômenos de construção de categorias de gênero. Refiro-me à presença ativa de dispositivos discursivos e perceptivos voltados para a inculcação das tradicionais diferenças de gênero, ${ }^{8}$ constituídas sobre a oposição funcional, complementar e hierárquica entre o que no século XIX se convencionou identificar como masculino e feminino. ${ }^{9}$ É examinando um feixe de processos convergentes desdobrados na longa duração histórica ${ }^{10}$ que penso ser possível alargar a nossa compreensão sobre esse fenômeno banal, mas não sem importância, que é a associação da identidade feminina à exibição do corpo.

No interior de um universo amplo e multifacetado, meu esforço de reflexão se fez sobre a circunscrição de matrizes materiais e suas ałualizações, entendidas como parte de um fenômeno complexo e difuso que sustenta o que entendemos como atributos 
de feminilidade. Compartilho a tese de que as mulheres ingressaram na modernidade de modo diferente dos homens. " Assim como as diferenças sociais, étnicas e econômicas significaram modos diferentes de inserção no sistema capitalista, também ser socialmente reconhecido como homem ou mulher teve implicações no modo de relacionamento com a cidade, com o trabalho, a casa, o consumo e assim por diante. Esła afirmação, para muitos óbvia, não o é na sua dimensão material. Estamos habituados a compreender tais diferenças no campo de disputa das ideias, dos discursos, acreditando que nossos corpos se alteram atendendo a determinações constituídas exclusivamente no universo abstrato das lutas políticas, econômicas e ideológicas. Pretendo discutir o assunto em outros termos, isto é, demonstrar o papel singular de artefatos na conformação de comportamentos e, especialmente, na reprodução de diferenças de gênero.

Estamos ligados aos objetos e aos hábitos que com ele desenvolvemos, bem como aos sentidos e às vantagens (ou desvantagens) que associamos a ele. ${ }^{12}$ Nossa identidade, inclusive a identidade de gênero, se constitui por meio de nossa relação com a materialidade do mundo e, é claro, podemos mudar, de fato mudamos, mas... como mudamos? Nenhuma mudança acontece a partir do nada, mudamos a partir de um repertório de coisas, sentidos e comportamentos herdados de outras gerações, e a experiência material é uma de nossas âncoras nas mudanças que vivenciamos..$^{13}$ Assim, tais heranças não existem na atualidade como meros sobreviventes, resquícios de outros tempos que insistem em nos acompanhar, pois elas são objetos tão contemporâneos quanto nossos smartphones e notebooks.

\section{O LUGAR DO ARTEFATO}

Antes de abordar meu objeto de análise, vale recuperar, ainda que sinteticamente, a discussão teórica que pôs em evidência o valor social estratégico dos artefatos na produção e conservação de categorias sociais.

Daniel Miller foi quem, em 1987, em livro seminal intitulado Material Culture and Mass Consuption, enfrentou o desafio de circunscrever teoricamente as especificidades dos artefatos na vida social. ${ }^{14}$ Afinal, se a dimensão material é intrínseca ao ser humano, como identificar nessa materialidade características que não estariam presentes em outras formas de expressão com alto grau de abstração, como a linguagem? Qual a diferença entre a linguagem (verbal e escrita) e o artefato? Miller buscou respostas que superavam a ideia de uma "gramática das coisas", já prenunciada por Pitt Rivers no século XIX ${ }^{15}$ e que foi levada ao extremo da sofisticação em análises da antropologia estrutural voltadas para a compreensão dos artefatos. ${ }^{16}$ Antecipando
11. Cf. Carvalho (2008), Miller (2000, p.71-92) e Souza (1987).

12. Miller (2000, p. 71-92).

13. Jodelet (1984, p. 358378).

14. Cf. Daniel Miller (2004, 2005).

15. Cf. Chapman,(1991).

16. Cf. Bourdieu (1970), Sahlins (1979), Baudrilard (2004) e Douglas (2011), entre outros. 
17. Boivin (2008, p. 129180).

18. Bourdieu (2009, p.87) define hábito como um "sistema de disposições duráveis e transponíveis, estruturas estruturadas predispostas a funcionar como estruturas estruturantes, ou seja, como princípios geradores e organizadores de práticas e de representações que podem ser objetivamente adaptadas ao seu objetivo sem supor a intenção consciente de fins e o domínio expresso das operações necessárias para alcançá-los".

19. Cf. Warnier (1999) as críticas que viriam na década de 1990, Miller procurou se afastar do modelo linguístico saussuriano ao perceber nele um fator reducionista, em que as características físicas dos artefatos só interessavam na medida em que eram socialmente apropriadas para produzir sentido. Fora de um sistema de comunicação, cujo funcionamento seguia o padrão abstrato e arbitrário da linguagem, a fisicalidade passava despercebida. ${ }^{17}$

Miller parte das abordagens teóricas referentes à formação do sujeito construídas por Piaget e Klein. Ambos desenvolveram modelos interpretativos dinâmicos para explicar o desenvolvimento da estrutura psíquica da criança em relação ao meio ambiente. A criança teria suas primeiras experiências de conhecimento de si e do mundo por meio da manipulação desafiadora de artefatos que permitiriam a constituição de significados abstratos sem, no entanto, a perda da concretude necessária para essa fase da vida. Miller sugere uma precedência dos artefatos na constituiç̧ão da dimensão simbólica. No entanto, conforme o indivíduo adquire aptidão para falar, a linguagem verbal invadiria o espaço da consciência, deslocando para o inconsciente a experiência e o conhecimento cotidiano adquiridos por meio dos objetos. Seria assim que se teria formado um verdadeiro abismo entre linguagem e percepção. A primeira seria lenta e pobre para descrever aquilo que percebemos de forma imediata e afásica. Experiências visuais, sonoras, táteis e olfativas como o reconhecimento de padronagens complexas, o discernimento de sabores de vinhos, de texturas e sonoridades escapariam à linguagem, que delas é capaz de falar de maneira muito restrita. Isso também valeria para a percepção inconsciente do papel normativo de certos objetos-chave como a moldura na obra de arte, a decoração na residência, etc.

A partir de uma abordagem que reconhece capacidades em estado de potência dos artefatos, Miller chega ao conceito de habitus ${ }^{18}$ de Bourdieu, como modelo interpretativo não reducionista que procura aplicar ao meio social aquilo que Piaget e Klein identificaram na formação primeira do indivíduo. No conceito bourdieusiano, a interação dinâmica com o meio social é vivida de forma inconsciente, como uma segunda natureza.

Também Warnier localiza na inconsciência aquilo que ele chamou de estereótipos motores, resultantes da interação do corpo com os artefatos, objetos naturais e meio físico. ${ }^{19}$ Nosso corpo teria a capacidade de utilizar a materialidade como extensão de nós mesmos, fazendo com que as dinâmicas dos objetos fossem incorporadas e memorizadas sem passar pela consciência. Igualmente para Latour, corpos humanos e artefatos agem uns sobre os outros, formando uma rede indissociável e estável. Sem os artefatos, como poderiam os humanos estender suas ações para além dos limites de seus corpos frágeis? Não é difícil imaginar que essa ampla rede de "humanos e não humanos" seria vivida sem a consciência plena de sua atividade. 
Níveis de inconsciência também são intuídos na interpretação que Alfred Gell faz dos efeitos dos atributos estéticos de artefatos sobre seu fruidor, tipo de agenciamento que ele nomeou como fascinação (captivation). A impossibilidade de compreender plenamente a fatura de uma obra de arte (ou artefatos com força estética) provocaria um "bloqueio cognitivo" vivenciado como "frustração prazerosa". ${ }^{20}$ Meneses e Pomian identificaram fascínio semelhante exercido por objetos que funcionam como pontes entre o mundo presente, visível, palpável e aquele distante e invisível. ${ }^{21}$ Baudrillard e Stewart reconheceram nos objetos antigos essa força de transcendência, vivida como um sentimento de nostalgia por um passado fictício, imaginado. ${ }^{22}$

É na perspectiva teórica aqui apresentada em suas linhas essenciais que pretendo tratar as esculturas decorativas de porcelana produzidas pela empresa Rebis.

\section{AS PORCELANAS REBIS}

Um dos objetos de nossa herança cultural que nos ajudam a entender o repertório material que alimenta a identidade feminina e sua relação com a exibição do corpo pode ser facilmente encontrado nos sites de vendas da internet. São bibelôs de porcelana feitos pela fábrica gaúcha Rebis. ${ }^{23}$ Esses bibelôs têm uma característica especial: são na sua maioria representações de damas e cavalheiros da aristocracia europeia do século XVIII (figura 1). Os modelos da Rebis foram feitos a partir de cópias modificadas de peças em porcelana trazidas de outra empresa produtora de fêtes galantes, a Renner, ${ }^{24}$ também gaúcha.

Sem conhecimento prévio sobre a produção das "estatuetas", Sergio Skopinski se tornaria em pouco tempo o único proprietário da empresa e a manteria ativa por 57 anos. Se já me causava espanto o surgimento de uma fábrica de bibelôs inspirados na iconografia galante em plena década de 1950, no Brasil, - que pensar do fato de que a produção conheceu seu ápice nos anos de 1980? Sérgio e seu braço direito, o sobrinho Marcos Roberto Ribeiro Santana, relataramme que chegaram a ter 35 funcionárias nesse período. Eram só mulheres, ${ }^{25}$ sem experiência com qualquer tipo de trabalho com porcelana. Com suas habilidades em costura e nas atividades de dona de casa, e seguindo a orientação dos proprietários, conseguiram fazer as matrizes das "estatuetas", suas formas e massa, conseguiram moldá-las, cozê-las em alta temperatura, aplicar pequenos ornamentos, pintá-las e fixar a pintura utilizando novamente os fornos (figura 2).
20. Cf. Alfred Gell (1998).

21. Cf. Meneses (1980) e Pomian (1984)

22. Cf. Baudrillard (2004) e Stewart (1993).

23. As informações sobre a Indústria e Comércio de Porcelanas Rebis Ltda foram obtidas por meio de entrevistas realizadas com o proprietário da empresa Sergio Skopinski e seu sobrinho Marcos Roberto Ribeiro Santana.

24. Sobre a atuação da Renner na produção de esculturas do gênero fêtes galantes ainda não existem estudos.

25. Sergio Skopinski, proprietário da empresa Rebis, contratou um artesão italiano que ficou pouco tempo na empresa e depois um moldador. 


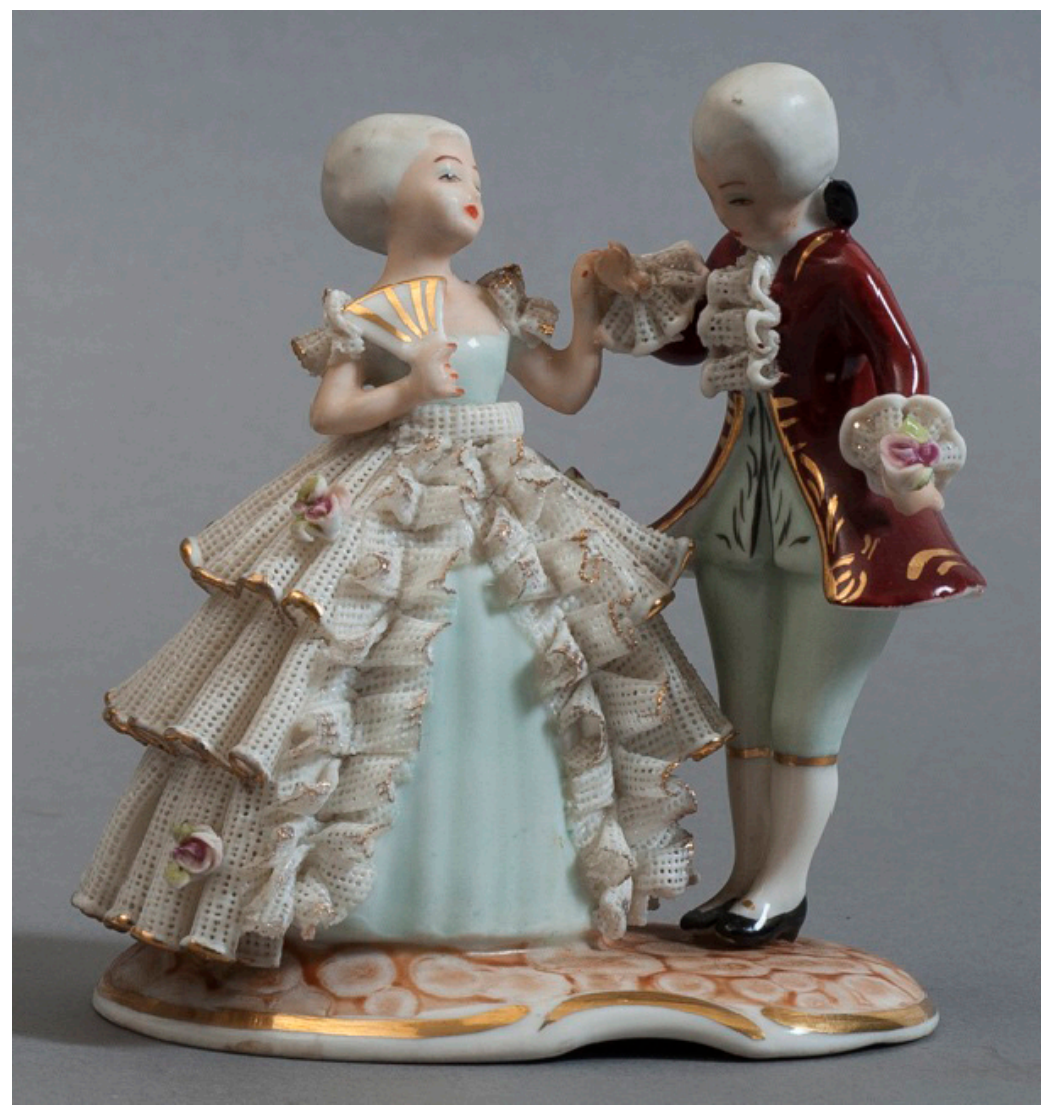

Figura 1 - Casal de fidalgos em porcelana denominado pelos fabricantes como Debutantes. $O$ modelo foi lançado em 1956 e produzido em quatro diferentes tamanhos. Indústria e Comércio de Porcelana Rebis, Porto Alegre, RS. Dimensões $9,5 \times 6,5 \times 11,0 \mathrm{~cm}$. Fotografia de José Rosael. Documento coletado em pesquisa de campo e em fase de patrimoniação no Museu Paulista da Universidade de São Paulo.

Figura 2 - Funcionárias da empresa Indústria e Comércio de Porcelanas Rebis Ltda. Fotografia de Shirley Skopinski, esposa de Sergio Skopinski, na década de 1980. No segundo plano da imagem, sobre a mesa, veem-se exemplares do casal de fidalgos da figura 1, ainda sem pintura, e a aplicação da saia rendada na dama. Documento coletado em pesquisa de campo e em fase de patrimoniação no Museu Paulista da Universidade de São Paulo.

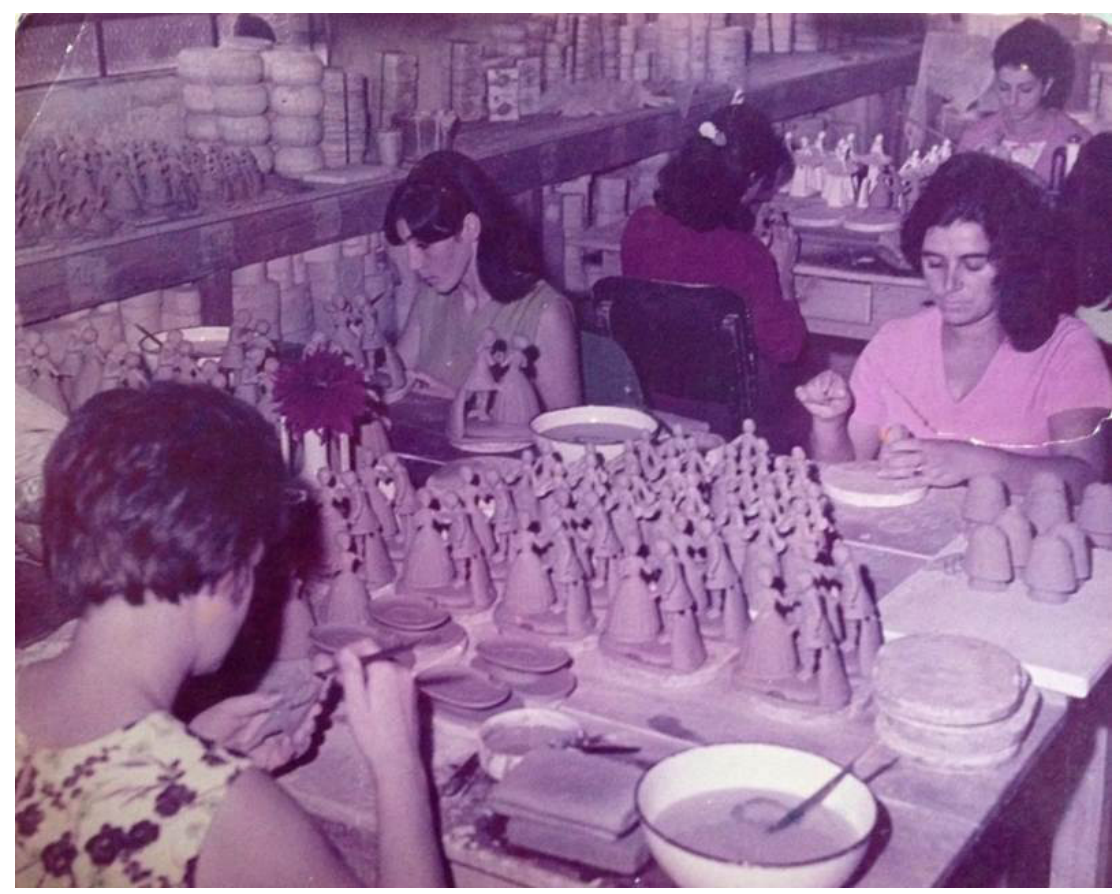


Estive em Porto Alegre para conhecer a fábrica Rebis, quando soube que ela fechara as portas há não muito tempo, em 2013. A fábrica iniciou suas atividades em 1956, quando o alemão Anton Steiner deixou a Renner, onde trabalhava como artesão, para abrir seu próprio negócio com dois outros sócios, o polonês Josef Bilan e o iugoslavo Ivo Res. Logo em seguida, um quarto sócio, brasileiro, filho de imigrantes poloneses, Sergio Skopinski, foi convidado a ingressar na empresa a fim de cuidar de sua administração e contabilidade.

Foi Sergio Skopinski que teve a ideia de fazer novas matrizes das mesmas imagens, mas em tamanhos diferentes, às vezes quatro variações do mesmo tema, menores do que as peças de origem, que podiam chegar a $29 \mathrm{~cm}$ de altura. $\bigcirc$ diferencial dessas peças, seu grande atrativo, eram as saias rendadas, feitas com tecido de algodão bem fino, pincelado com massa de porcelana e, depois, aplicado e moldado no corpo da figura feminina, como parte de suas saias, mangas e decotes e também nos detalhes da camisa dos cavalheiros.

As vendas se concentravam em São Paulo e Rio de Janeiro, além da região nordeste do país. A Rebis nunca fez propaganda em qualquer mídia, apenas decalcava seu telefone nas peças que produzia. Renner e Rebis produziram suas peças a partir de modelos retirados do vasto repertório europeu.

\section{AS FÊTES GALANTES}

As fêtes galantes surgiram em pinturas a óleo e esculturas de porcelana feitas, muitas vezes, pelos mesmos artistas, que também utilizaram gravuras para difundir suas criações, o que teria mudado a escala de circulação dessas imagens. ${ }^{26}$ As fêtes galantes representavam a aristocracia em situações de ócio - lendo, tocando instrumentos musicais, em refeições ao ar livre, em pausas durante a caça, colhendo frutos, flores, descansando em meio a paisagens idílicas, em situações que propiciavam o encontro entre os sexos e, com isso, gestos de sedução e cortesia. ${ }^{27}$

Em todas essas cenas os corpos são representados em movimentos nada aleatórios, ao contrário, os personagens se apresentam em uma coreografia elegante e graciosa, deixando claro que a dança era uma referência central para esse tipo de iconografia. Não foi por acaso que, de todo o complexo conjunto de esculturas do gênero fête galante, produzido nos séculos XVIII e XIX, a representação do casal, em que se insinua o convite para a dança, tenha permanecido como a "síntese" do repertório que chegou ao século XX.
26. Cf. Wilhelm; Reber (1980).

27. Cf. Unruh (2008) 
28. Cf. Hellman (1999, 2004).

29. Cf. Sharp (2004).

30. Cf. Veblen (1983, p. 5-48) e Montgomery (1998).
A dança era o momento mais importante de demonstração das habilidades da aristocracia setecentista para a vida em sociedade. Parte dessas habilidades era apresentar-se aos outros como um ser elevado, de espírito e de corpo. Roupas e acessórios ajudavam na metáfora do ser etéreo: sapatos com saltos altos usados por ambos os sexos, vestidos femininos cobrindo os pés, casacas masculinas estruturadas para afastar do corpo as abas frontais, de modo a dar a aparência de leveza a seus usuários. A cenografia aristocrática se desenrolava em movimentos graciosos, que aconteciam amparados por um parceiro de dança ou por objetos extremamente sofisticados. Os códigos de etiqueta tinham como base filosófica um modo de ser em que se buscava agradar o outro por meio de comentários afáveis e espirituosos. Tratava-se de conquistar a atenção do outro não por meio do confronto, do argumento ou da agressão verbais, mas por meio de uma performance pessoal e retórica voltada para a sedução no seu sentido mais amplo: sedução intelectual, amorosa, sexual e classista. $\bigcirc$ tempo ocioso da aristocracia deveria ser aplicado na produção de roupas, acessórios, gestos, tons de voz e erudição mobilizados para causar uma espécie de encantamento. Parte desse encantamento se devia à maneira "natural" com que essas pessoas se faziam diferentes e especiais. ${ }^{28}$

Quando lemos os manuais de etiqueta do século XIX, notamos uma mudança significativa. Os atributos antes próprios de homens e mulheres nobres foram redirecionados para as mulheres burguesas da alta sociedade e, por extensão, tornaram-se objeto de desejo das mulheres das classes médias. A ostentação de uma indumentária rica em ornamentação, exibindo temas florais, múltiplas cores e brilhos, antes utilizada por homens e mulheres aristocratas, tornase uma prática ressignificada de modo a alimentar o que alguns identificaram como uma "cultura feminina". ${ }^{29}$ Assim, a exibição transforma-se em um modo de ser das mulheres, que são orientadas a se portar socialmente de modo que sua presença cause impacto sem, no entanto, confrontar seus convidados. Uma mulher culta e educada não deveria fazer uso de sua inteligência para criar cisões, tensões ou conflitos, comportamentos e qualidades próprias, agora, dos homens. A orientação que a ensaísta da Folha de S.Paulo Tati Bernardi recebeu de ser mais feminina, sorrir mais, concordar mais... remete-nos à reformulação de práticas anteriores de altíssimo prestígio e que foram redirecionadas para constituir um modo feminino e que não se limita, mesmo hoje, à pura disponibilidade sexual. As técnicas psicomotoras bem como os repertórios visuais e materiais produzidos pela aristocracia de corte do século XVIII forneceram os elementos essenciais para o que no século XIX ficou conhecido como mulher-ornamento ou, no avançar do século XX, como a esposa culta e educada, preparada para transformar em dividendos sociais o sucesso do marido no trabalho. ${ }^{30}$ 
gosto pelos bibelôs galantes em pleno século XX segue esse caminho de ressignificações de valores de modo a circunscrever a mulher ao espaço da casa e às funções de oposição ao trabalho e de oposição à liberação feminina em geral. Esses objetos são parte de um processo social cuja trajetória entrou em convergência com outros processos associados às reconfigurações das funções e identidades dos gêneros masculino e feminino.

\section{AS BAILARINAS}

Outra dessas trajetórias diz respeito ao desenvolvimento do ballet clássico. Sua história, aparentemente autônoma e tão cheia de particularidades, também colaborou para a associação da identidade feminina à exibição do corpo. Em 2012 o país possuía 500 escolas de dança, tendo o ballet clássico como a técnica predominante. A estas escolas estão associados cerca de 1500 profissionais da dança. ${ }^{31}$ Quando perguntei a Marcos Santana, da fábrica de porcelanas Rebis, qual era a "estatueta" mais vendida, ele não hesitou em dizer que era a bailarina (figura 3).

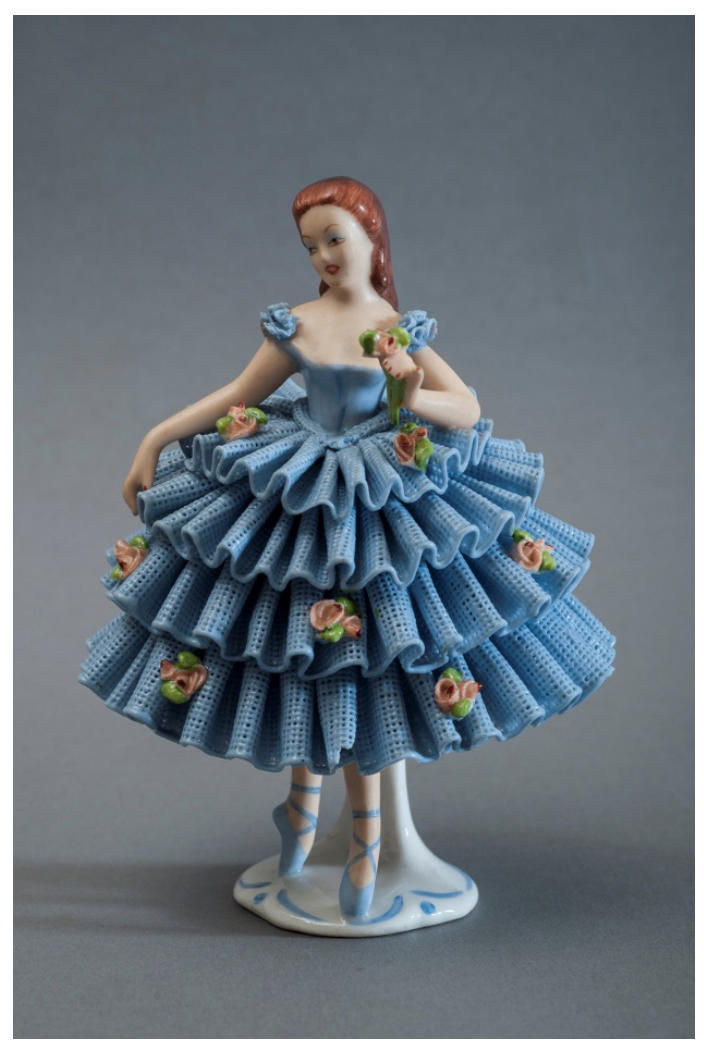

Figura 3 - Bailarina em porcelana. A matriz de 1956 foi produzida até 2013 pela Indústria e Comércio de Porcelana Rebis, Porto Alegre, RS. Dimensões $10 \times 7,5 \times$ $13,5 \mathrm{~cm}$. Fotografia de José Rosael. Documento recolhido em pesquisa de campo e em fase de patrimoniação no Museu Paulista da Universidade de São Paulo. 
32. Portinari (1989, p. 62).

33. Bourcier (2001, p. 115)

e Kraus et alii (1991, p. 74).

34. Bourcier (op. cit., p. 1534).

35. Ibid., 2001, p. 156.

36. Portinari (1989, p. 70).

37. Bourcier (2001, p. 161).

38. Portinari (1989, p. 71).

39. O entrechat é um tipo de salto durante o qual os pés do bailarino se cruzam rapidamente.
O balé, ou balé clássico, difundido entre as crianças, especialmente entre as meninas, ainda hoje vai ao encontro do desejo dos pais de ver seus filhos terem um bom desempenho. Nesse caso específico, trata-se de incentivar nas meninas certo tipo de feminilidade associada ao controle do corpo, capaz de empreender gestos e poses consideradas elegantes, delicadas e que exigem um treino especializado para serem realizadas. Esse condicionamento físico se refletiria, por fim, nos gestos e posturas cotidianas, tornando a menina especialmente bela.

A técnica clássica nasceu na realeza francesa e italiana, onde a dança fazia parte da educação da nobreza. Os próprios nobres desempenhavam o papel de bailarinos. ${ }^{32}$ Charles-Louis-Pierre de Beauchamps, professor de dança do rei Luís XIV, tomando como referência as técnicas de dança do Renascimento italiano, estabeleceu as cinco posições básicas que são seguidas até hoje. ${ }^{33}$

No século XVIII, os passos de dança se sofisticaram, sendo notável que, em 1700, Raoul-Anger Feuillet registre em publicação a existência de 460 passos distintos. ${ }^{34} \mathrm{~A}$ multiplicação de manuais de dança garantiu que as técnicas clássicas se divulgassem para além da nobreza, atingindo também os extratos urbanos abastados que, ciosos do prestígio a elas conferido, começaram a frequentar os espetáculos de balé. ${ }^{35}$ Mas não foram somente os manuais que garantiram a difusão do balé. O seu ingresso no teatro foi fundamental. No início do século XVIII o balé já contava com dançarinos profissionais se apresentando em teatros. ${ }^{36}$

As mulheres que atuavam nos balés de ópera usavam vestidos compridos com passamanarias e bordados, armados com crinolinas e suspensos por sapatos de salto alto. A tradição nobre de exibir o corpo longe do chão, em atitude elevada, levou à criação do salto agulha, que, por sua vez, virou moda para além dos palcos. ${ }^{37}$ Foi Marie-Anne Cupis de Camargo, bailarina do Opéra de Paris, que encurtou sua saia em mais de um palmo para poder saltar e executar passos rápidos, antes reservados somente aos homens. ${ }^{38}$ No final do século XVIII, a vontade de tornar seus personagens etéreos levou o bailarino e coreógrafo francês Charles-Louis Didelot a usar, em 1796, na coreografia Flora e Zéfiro, a máquina de voar. Didelot inventou um dispositivo que prendia os bailarinos a fios para que estes conseguissem se manter na ponta dos pés.

A elevação de braços, pernas e corpo com saltos, piruetas e entrechats ${ }^{39}$ passou a ser muito explorada nas apresentações em teatro. Essa valorização está relacionada com o local de onde a plateia assistia à apresentação. $\bigcirc$ que antes era contemplado em linha horizontal, no teatro passa a ser visto de frente, pois o espaço se comprimiu para adaptar-se à largura do palco, que ficava ainda em plano superior ao espectador, fazendo com que este observasse o desenrolar da 
coreografia de baixo para cima. $\bigcirc$ espaço vertical passa, então, a ser o organizador das performances dos bailarinos. ${ }^{40}$

balé torna-se uma forma de expressão independente da fala, baseado somente em movimentos e gestos organizados em torno de um enredo e interpretação de personagens. No início do século XIX, o virtuosismo técnico ganhou ainda mais leveza com a invenção do arabesco, posição de arremate de uma sequência de movimentos em que a bailarina se apoia em um dos pés e levanta o outro para trás, fazendo os braços acompanhar o movimento das pernas, criando linhas paralelas ou uma longa linha que se estende dos dedos do pé de apoio aos dedos da mão do mesmo lado.

A essa posição foi acrescida a invenção das pontas, técnica em que a dançarina sustenta o peso do corpo sobre as pontas dos dedos dos pés, mantendo-se nessa posição prolongadamente de modo estático ou em movimento. Geneviève Gosselin praticava a ponta desde 1813. Antes dela a ponta foi usada brevemente, apenas para acentuar uma postura elevada. A essa altura, o calçado urbano de salto já tinha sido substituído pelas sapatilhas flexíveis com enchimento de algodão e reforço de galões e bordados. A dançarina sustentava-se graças ao seu equilíbrio e à força de seus músculos. Depois de Gosselin, Amélia Brugnoli também usou as pontas, técnica que será amplamente difundida e consagrada pela dançarina italiana Marie Taglioni. ${ }^{41}$ Usando o "tutu romântico" desenhado por Eugene Lami, feito de camadas de saias semitransparentes de musselina branca, em altura que deixava as panturrilhas expostas, e associado a um corpete justo com ombros e espáduas nus, Taglioni dançou A Silfide nos principais teatros do mundo, como a Opéra de Paris, o Covent Garden de Londres, o Teatro Marie de Moscou e o Scala de Milão. $O$ tema da peça, ${ }^{42}$ o amor entre um mortal e um espírito, exigia uma presença no palco quase irreal, cheia de graça e suavidade. À sua indumentária leve, Taglioni associou o uso contínuo das pontas. ${ }^{43}$ Para os teóricos da dança, a sapatilha de ponta "veio realizar o ideal de imaterialidade, espiritualidade, visão diáfana e alada e que se tornaria definitivamente o símbolo da bailarina clássica". ${ }^{44}$

A figura feminina da bailarina torna-se dominante. A coreografia é concebida para ela, que se utiliza do homem apenas como ponto de apoio ou para lançá-la ao ar. ${ }^{45}$ As bailarinas famosas eram retratadas nos ateliês fotográficos, em formato carte de visite, e suas imagens circulavam pelo mundo como símbolo de beleza feminina. Executado na Inglaterra desde Henrique VIII, e tendo como focos difusores a França e a Itália, o balé passou a ser praticado em Prússia, Dinamarca, Suécia, Portugal, Espanha, Rússia e Estados Unidos.
40. Caminada (1999, p. 107, 137).

41. Bourcier (2001, p. 2012).

42. La Sylphide marca a estreia do primeiro balé romântico, em 1832 . Caminada assim define o enredo do balé: "um ser alado, a Sílfide, se apaixona por um mortal, James, atraindo-o durante a sua festa de noivado com Effie, para uma floresta. Madge, uma bruxa que havia sido expulsa da festa pelo próprio James, vinga-se, enfeitiçando um xale que oferece ao rapaz, dizendolhe que, ao ser envolvida pelo xale, a Sílfide perderia sua asas e se deixaria prender definitivamente; $o$ que James desconhecia é que a vida dela residia nas asinhas; assim que as perde, perde também a vida." (1999, p. 139). Sílfide define na mitologia celta e germânica da Idade Média o gênio feminino do ar. Com o sucesso da peça, o termo passa a definir uma mulher magra, delicada e com cintura muito fina.

43. Cf. Angélica (2015).

44. Caminada (1999, p. 137).

45. Bourcier (2001, p. 202-4) e Portinari (1989, p. 87). 
46. Louis Lacombe foi o primeiro "maestro de danças" do Brasil. Chegou em 1811 com a função de "ensinar à nobreza e à família real as danças de salão da época e encenar pequenos números dançados para os intervalos de montagens líricas". Caminada (1999, p. 354).

47. Portinari (1989, p. 77).

48. Maria Olenewa formouse na Academia de Dança Nelidova, em Moscou. Após 1917, por causa da Revolução, exila-se na França e chega ao Brasil com o grupo de bailarinos de Leonide Massine. Participou das temporadas líricas na cidade do Rio de Janeiro em 1923 e 1924. Entre 1927 e 1942 foi diretora da Escola de Danças do Teatro Municipal e a partir de 1936 do Corpo de Baile do Teatro. Exonerada em 1942, foi para São Paulo, onde dirigiu a Escola Municipal de Dança da Prefeitura e, posteriormente, passou a atuar em sua própria escola. Suicidou-se em 1965. Caminada (1999, p. 357).

49. Portinari (1989, p. 13 , 236).

50. Ibid., 1989, p. 358-366.

51. Caminada (1999, p. 358).

52. Portinari (1989, p. 2378).
No Brasil, o casamento de D. Pedro I com Dona Leopoldina, realizado em maio de 1818, foi comemorado com a apresentação de um balé coreografado por Louis Lacombe, ${ }^{46}$ com cenário desenhado por Debret. ${ }^{47}$ Ao longo do século XIX, as companhias de balé francesas e italianas apresentavam-se no Rio de Janeiro e em Buenos Aires. O Teatro Municipal do Rio de Janeiro, inaugurado em 1909, procurou atender às exigências técnicas das companhias estrangeiras que passavam pela cidade. Com a presença no país dos bailarinos russos, o balé passou a ser fomentado para além de círculos elitizados. Uma breve retomada dos principais empreendimentos responsáveis pela sua difusão faz-se necessária para que o leitor tenha uma ideia de sua possível associação ao sucesso das estatuetas da Rebis que retrataram bailarinas desde a década de 1950, com ápice de vendas nos anos de 1980.

Desde a segunda metade do século XIX, o centro irradiador do balé clássico havia se deslocado para a Rússia. Nijinsky apresentou-se no Rio de Janeiro em 1913. Mas foi com Maria Oleneva, ${ }^{48}$ da Cia. de Anna Pavlova, que o ensino ganhou corpo no país. Radicada no Brasil em 1927, Oleneva criou a escola de dança no Teatro Municipal do Rio de Janeiro e formou a primeira geração de profissionais que atuariam no corpo de baile do teatro. ${ }^{49} \bigcirc$ Brasil, a partir da atuação de Oleneva, ingressou no mercado da dança e passou a atrair bailarinos e coreógrafos dos centros formadores desses profissionais, especialmente aqueles fugidos da União Soviética ou mesmo da II Grande Guerra. Foi o caso de Maryla Gremo, polonesa, que em 1943 tornou-se maîtresse de balé e coreógrafa do Teatro Municipal do Rio de Janeiro e em 1947 assumiu a direção artística do Ballet da Juventude. Em 1943, o bailarino Yurek Shabelevski deixa o Original Ballet Russe para tornar-se orientador do Ballet do Teatro Municipal do Rio de Janeiro (BTMRJ). Madeleine Rosay dirigiu o BTMRJ e a Escola de Dança em 1949. Sua atuação foi importante para a difusão do balé, pois nos anos de 1960 fez programas de televisão, além de escrever sobre dança na revista Querida. Passaram pelo BTMRJ coreógrafos e bailarinos renomados como Leonid Massine, Harald Lander, William Dollar, Alícia Alonso, lgor Youskevitch, Alicia Markova, Oleg Brianski, Nora Kovach e Istvan Rabovski. 50 ○ Original Ballet Russo permaneceu "refugiado" na América Latina e, em 1945, o Rio de Janeiro pode assistir a $\bigcirc$ Lago dos Cisnes, Les Sylphides e outros clássicos românticos. Na década de 1940, o BTMRJ fez espetáculo ao ar livre, no Jardim de Alá. ${ }^{51}$ Na década de 1950, a imprensa ampliou a divulgação da dança, surgiu a revista especializada Rio-Ballet e Tatiana Leokova, francesa de origem russa, remontou no país os pas-dedeux mais famosos. ${ }^{52}$ Em 1954, ano de comemoração do IV Centenário de Fundação da cidade de São Paulo, foi criado o Ballet do IV Centenário, que estreou em apresentação no Ginásio do Pacaembu, outra oportunidade de divulgação mais 
ampla da dança. Em 1959, a soviética Eugenia Feodorova encenou pela primeira vez nas Américas a versão completa de $\bigcirc$ Lago dos Cisnes, criou em 1961 a Fundação Brasileira de Ballet e encenou a versão completa de Coppelia, também pela primeira vez no Brasil. 53

Além de Rio de Janeiro e São Paulo, outras cidades passaram a contar com profissionais de dança: Escola Municipal da Cidade de Santos; Companhia de Ballet da Cidade de Niterói; Balé do Teatro Guaíra, de Curitiba; Ballet da Fundação das Artes, em Belo Horizonte; Ballet do Teatro Castro Alves, em Salvador; nesta mesma cidade, o Ballet Brasileiro da Bahia; Ballet de Minas Gerais (atual Cia. de Dança do Palácio das Artes); Escola Municipal de Dança de Londrina, sem contar a disseminação de escolas particulares no Rio de Janeiro e São Paulo. ${ }^{54}$

Nas décadas de 1960 e 70, o balé no país já tinha se consolidado como campo artístico, com pessoas capazes de formar profissionais, com atuação em governos locais, ensino e escoladas privadas, promoção de encontros e festivais, sindicato, acesso à mídia escrita e televisiva. As estratégias de difusão são diversas e pode-se ter uma ideia do empenho dos profissionais por meio da atuação do Balé Guaíra, que desenvolveu projeto de formação de plateia, em que eram apresentados espetáculos para escolas de primeiro e segundo graus.

A década de 1980 conheceu uma nova guinada do balé no Brasil. $\bigcirc$ Teatro Municipal do Rio de Janeiro contratou Dalal Achcar, carioca de origem libanesa, para dirigir a companhia de balé. Com o nome de Ballet do Teatro Municipal, o corpo de bailarinos do teatro ganhou novo status. Ampliado e renovado, Dalal empenha-se em fazer grandes produções patrocinadas pela Souza Cruz. ${ }^{55} \bigcirc$ Sindicato dos Profissionais da Dança do Estado do Rio de Janeiro (SPDRJ), fundado em 1985, foi uma das maneiras de organizar os profissionais da área e ampliar sua atuação, inclusive com propostas de introdução da dança no currículo das escolas de ensino fundamental e médio. ${ }^{56}$ Foi nesse contexto que surgiu a bailarina Ana Botafogo.

Ana Botafogo começou sua carreira em 1975, e em 1978 já era a primeira bailarina do Balé Guaíra, de Curitiba, onde encenou Giselle, outro clássico do balé romântico. Em 1981, Botafogo tornou-se a primeira bailarina do BTMRJ, estreando no papel principal da obra Coppelia, e como tal percorreu o país fazendo apresentações. ${ }^{57}$ Dançou A Bela Adormecida, $\bigcirc$ Quebra-Nozes, Giselle, Romeu e Julieta, La Sylphide, Dom Quixote, La Bayadéré, O Lago dos Cisnes, A Megera Domada e Eugene Onegin, entre outras obras que consagraram o balé clássico. No site oficial da bailarina há um elenco impressionante de títulos e prêmios recebidos pelo reconhecimento de seu trabalho: Embaixatriz da Cidade do Rio de Janeiro, Benemérita do Estado do Rio de Janeiro, Chevalier Dans L'Ordre
53. Caminada (1999, p. 3667).

54. Portinari (1989, p. 240) e Caminada (1999, p. 43842).

55. Portinari (op. cit., p. 239).

56. Caminada (1999, p. 3767).

57. Ibid., 1999, p. 422. 
58. Cf. Botafogo (2016).

59. Cf. A\&E Television (2015). dês Arts et dês Lettres (outorgado em 1997 pelo Ministério da Cultura da França), Troféu Mambembe, referente ao ano de 1998, pelo reconhecimento do conjunto de seu trabalho e divulgação da dança em todo o território nacional, Ordem do Mérito Cultural, na classe de Comendadora, pelas contribuições prestadas à cultura no país (2002), Medalha de Mérito Pedro Ernesto da Câmara Municipal do Rio de Janeiro (2004). ${ }^{58}$ É possível que a trajetória da bailarina mais popular do país esteja associada ao sucesso da escultura da bailarina da Rebis e ao boom de vendas conhecido pela empresa na década de 1980.

\section{AS CINDERELAS}

Um terceiro e último fenômeno que converge com os anteriores aqui apresentados, desaguando na "cultura feminina" da exibição do corpo, é de natureza visual e pode ser exemplificado na trajetória do conto de fadas Cinderela. A história, gestada na tradição oral, foi escrita pela primeira vez por Charles Perrault, que em 1697 publicou o livro que ficou conhecido como Contos da mamãe gansa.

Cinderela foi adaptado para óperas desde 1749. Foram muitas as versões para balé a partir de 1893. As adaptações para o teatro tiveram início no século XX, mas sua versão mais conhecida é sem dúvida a de Walt Disney, lançada em 1950 como desenho animado adaptado da versão do conto dos Irmãos Grimm. O filme teve uma audiência espetacular e retirou a empresa Disney do vermelho depois dos fracassos de bilheteria que foram Pinóquio, Fantasia, Dumbo e Bambi, lançados entre 1940 e $1942 .{ }^{59}$

A história, como todos sabem, é a de uma moça órfã submetida a trabalhos domésticos pesados, alijada de seu direito de usufruir da vida e do afeto familiares e alvo de incontáveis maldades engendradas por sua madrasta e suas duas filhas. Cinderela era uma jovem mulher que causava inveja pela sua beleza e nobreza de espírito, faltando-the apenas alguns bens materiais para tornar evidente a sua vocação para a realeza, o que acontece em um passe de mágica no dia do baile em que o príncipe escolheria sua futura esposa. Sua fada madrinha lhe fornece uma carruagem, quatro cavalos, dois cocheiros, um criado, um vestido e um par de sapatinhos de cristal. De posse temporária de seus novos pertences, Cinderela impressiona o príncipe, porém foge antes que ele conheça a sua verdadeira identidade. Desfeita a magia, restou apenas o sapatinho de cristal, o único elo entre a Cinderela do baile e aquela pobre moça. $\bigcirc$ sapatinho 
só servirá no pé daquela a quem ele realmente pertence. É a natureza bela e boa de Cinderela, seu bem inalienável, que faz com que o sapatinho the sirva, mostrando ao público que a riqueza material e a felicidade conjugal são decorrências ou mérito da nobreza de caráter.

Recentemente, esteve em tela o filme Cinderela de Kenneth Branagh, produzido em 2015 (figura 4). A versão é muito fidedigna ao desenho de Walt Disney. $O$ ponto alto do filme é a dança do casal no grande baile. Em um vestido magnífico, Cinderela exibe uma coreografia complexa, mesclando gestos de braços e pernas que só poderiam ser tão sincronizados com os do príncipe depois de muito tempo de ensaio. No entanto, apesar de não fazer parte dos bens cedidos por magia, Cinderela dança de maneira impecável. É verdade que a mãe de Cinderela, no leito de morte, lembra-lhe de duas máximas para a vida - ser corajosa e gentil. Entretanto, não há indicação no filme de que nossa heroína tenha tido aulas de dança ou de etiqueta suficientes para justificar uma performance tão espetacular.

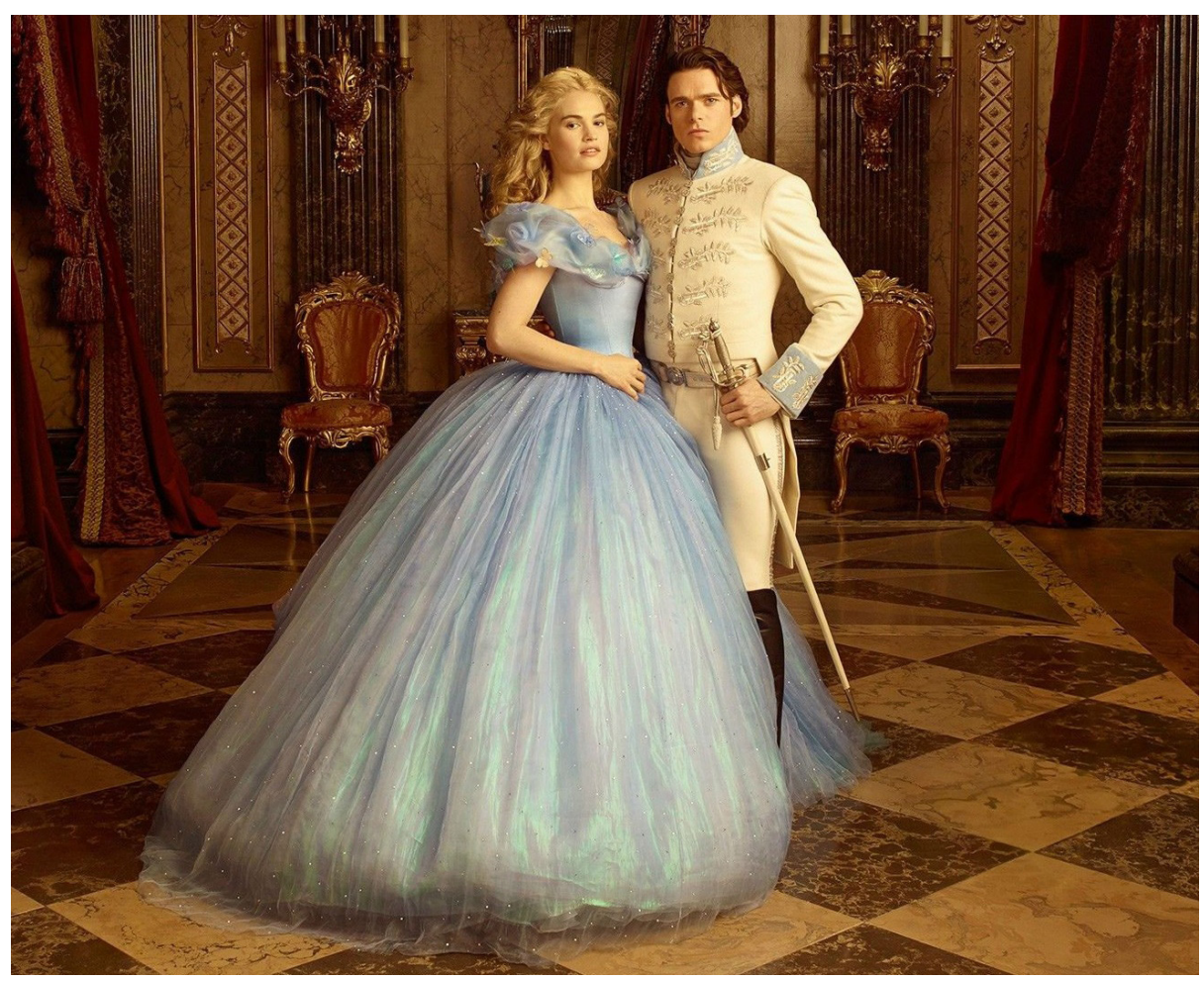

Figura 4 - Peça publicitária do filme Cinderela, dirigido por Kenneth Branagh, roteiro de Chris Weitz, com Lily James como Cinderela e Richard Madden como o Príncipe Encantado. Produzido para a Walt Disney Pictures. 
60. Evidentemente, refirome a uma inspiração, pois o filme não tem qualquer compromisso com a fidedignidade estilística ao referir-se ao século XVIII ou ao XIX. A sobriedade do vestido de Cinderela, feito em uma única cor, lembra ainda a apropriação que Dior fez do mesmo período. O new look foi uma síntese de certo modo paradoxal de alto luxo e austeridade.
A naturalização das técnicas corporais são as mesmas que, na corte da aristocracia francesa do setecentos, garantia o encantamento daqueles que sabiam desempenhar a verdadeira prática cortês. Ao fenômeno de naturalização, some-se a beleza ariana da personagem. Ainda que na versão contemporânea a madrasta, Lady Tremaine, seja interpretada pela estonteante Cate Blanchett, Cinderela jamais foi representada como uma mulher sem beleza. Lembremos ainda que o ambiente sugerido para o desenrolar da história é aquele do século XVIII e da retomada do rococó no século XIX ${ }^{60}$ e que o casal Cinderela e príncipe (figura 4) bem poderia ser um entre tantos pares escultóricos das fêtes galantes, inclusive aquele produzido pela Rebis para enfeitar nossas residências.

\section{COMENTÁRIOS FINAIS}

Temos aqui um repertório de mais de 250 anos revivificado e em plena atividade. Por que esses objetos manteriam sua vitalidade? A pista para uma resposta à questão pode estar no fato de que o casal de "fidalgos" (figura 1) foi intitulado na lista de venda da fábrica Rebis como "Debutantes". Se observarmos as feições dessa escultura, perceberemos que, de fato, ela parece representar pessoas muito jovens, quase adolescentes. Some-se a isso o fato de que a diminuição dos formatos dessas esculturas, chegando à altura de $9,5 \mathrm{~cm}$, indicaria algo mais que a possibilidade de vendê-las por um preço menor e com isso atingir novos consumidores. A diminuição de tamanho e a juventude ressaltada do casal indicariam uma mudança do lugar na casa desses objetos decorativos - da sala de visitas para os quartos das meninas.

Objetos delicados na confecção e frágeis na manutenção, as esculturas de porcelana exigem cuidados de suas proprietárias. Um dos fatores de prejuízo para a empresa Rebis era a necessidade de substituição de peças quebradas nas lojas. Essas esculturas não valem apenas pelo que representam, elas agem como um controlador, ainda que sutil, uma espécie de lembrete, do comportamento que se espera das meninas. Para manter o vestido rendado de porcelana íntegro é preciso saber manipular o objeto com delicadeza. $\bigcirc$ espaço em torno do objeto também deve ser controlado, para que a escultura não tombe e tenha o seu vestido arruinado. Tais cuidados exercidos com a coleção de bibelôs podem muito bem se expandir para todo o quarto da adolescente. A escultura se torna assim um agente com efeito pedagógico. 
As qualidades materiais de tais artefatos associam-se aos seus significados. Nos sites de venda em que esculturas de porcelana do gênero fête galante são vendidas, aparece o título atribuído pelo vendedor como "casal romântico". Em uma sociedade em que as mulheres conquistam espaços públicos, ingressam no mercado de trabalho, tornam-se autônomas, inclusive tendo a opção de não se casarem, a festa de debutantes (realizada ou apenas sonhada) é um momento em que essas mulheres estão ainda sob o controle dos pais, que se veem em condições de fomentar em suas filhas os sentidos tradicionais associados à identidade feminina. A exaltação do casal que a escultura promove, idealizando não apenas uma mulher elegante e voltada para as atividades sociais de entretenimento, mas um homem solícito e companheiro, age na contracorrente da diluição das diferenças de gênero, atualizam significações e compensam angústias vividas perante tantas mudanças de lugares e de valores.

Evidentemente, tais artefatos escultóricos não atuam sozinhos, eles devem ser entendidos como parte de uma rede de práticas sociais que, ao convergirem, se retroalimentam - danças, filmes, fantasias de princesas, bonecas.

É do encontro entre as questões atuais de gênero e o conjunto de artefatos, técnicas corporais e imagens visuais que vem a força das apropriações realizadas pela sociedade ocidental com o objetivo de dar nova vida a funções tradicionais associadas a homens e mulheres. 


\section{REFERÊNCIAS}

FONTES MANUSCRITAS

CINDERELLA Movie. 2016. 1. Ilustração. Peça publicitária. Walt Disney Pictures. Disponível em: <https://bit.ly/32hXHNC>. Acesso em: 10 out. 2019.

ROSAEL, José. Debutantes. [s. d.], São Paulo. 1. Fotografia. Modelo produzido por Indústria e Comércio de Porcelana Rebis, Porto Alegre, RS. Dimensões 9,5 x 6,5 x11,0 cm. Acervo do Museu Paulista da Universidade de São Paulo.

ROSAEL, José. Bailarina em porcelana. [s. d.], São Paulo. 1. Fotografia. Modelo produzido por Indústria e Comércio de Porcelana Rebis, Porto Alegre, RS. Dimensões 10 x 7,5 x 13,5 cm. Acervo do Museu Paulista da Universidade de São Paulo.

SKOPINSKI, Shirley. Funcionárias da empresa Rebis. [198?], Porto Alegre. 1. Fotografia.

LIVROS, ARTIGOS E TESES

ANGELICA, Carina. A história do ballet clássico. [s. 1., s. d.]. Disponível em: <https://bit. ly/2qFKobU>. Acesso em 26 jun. 2015.

ARDENER, Shirley (ed.). Women and Space. Ground Rules and Social Maps. Oxford; New York: Berg, 1997, p. 46-69.

BAUDRILLARD, Jean. O sistema de objetos. $4^{\mathrm{a}}$ ed. São Paulo: Perspectiva, 2004 [1 $^{\mathrm{a}}$ ed. francesa 1968]. p. 21-71.

BERNARDI, Tati. Não quero transar. Folha de S.Paulo, 5 jun. 2015.

BOIVIN, N. The Agency of Matter. Material Cultures, Material Minds. The impact of things on human thought, society, and evolution. Cambridge: Cambridge University, 2008. p. 129-180. 
BOTAFOGO, Ana. Site oficial. Disponível em: <https://www.anabotafogomaison.com.br/namidia/>. Acesso em: 4 nov. 2029.BOURCIER, Paul. História da dança no ocidente. São Paulo: Martins Fontes, 2001.

BOURDIEU, Pierre. The Berber house or the world reversed. Social Science Information, v. 9, p.151-170, apr. 1970 .

BOURDIEU, Pierre. O senso prático. Petrópolis: Vozes, 2009.

CAMINADA, Eliana. História da dança. Evolução cultural. Rio de Janeiro: Sprint, 1999.

CARVAlHO, Vânia Carneiro de. Gênero e artefato: o espaço doméstico na perspectiva da cultura material. São Paulo: Edusp; Fapesp, 2008.

CARVALHO, Vânia Carneiro de; LIMA, Solange Ferraz de. Individuo, Género y Ornamento em los retratos fotográficos, 1870-1920. In: AGUAYO, Fernando; ROCA, Lourdes (orgs.). Imágenes e Investigación Social. México: Instituto Mora, 2005, v. 1, p. 271-291.

CERRI, Luís Fernando; SILVA, José Alexandre. Norbert Elias e Pierre Bourdieu: biografia, conceitos e influências na pesquisa educacional. Linhas, Florianópolis, v. 14, n. 26, p. 171-198, jan./jun. 2013.

CHAPMAN, William. 'Like a game of dominoes': Augustus Pitt Rivers and the typological museum idea. In: PEARCE, Susan (ed.). Museum Economics and the Community. Londres, Atlantic Highlands: The Athlone, 1991, p. 135-176.

COlOMinA, B. (ed.). Sexuality \& Space. Princeton: Princeton Architectural, 1992.

DOUGLAS, Mary. Food as a system of communication. In: DOUGLAS, Mary. In the Active Voice. Londres; Nova York: Routledge, 2011. [Routledge Revivals, $1^{\text {a }}$ ed. 1982].

FOUCAULT, Michel. Vigiar e Punir: Nascimento da Prisão. Rio de Janeiro: Petrópolis, 1977.

FRANÇA, Thamires. Um resumo da história do ballet no Brasil. 2012. Disponível em: <https:// bit.ly/32RuVDV.> Atualizado em: 2 jan. 2012. Acesso em: 5 mar. 2016.

GELL, A. Art and Agency. Oxford: Oxford University Press, 1998. 
GRAZIA, Victoria de.; FURLOUGH, Ellen. (eds.). The Sex of Things: Gender and Consumption in Historical Perspective or You Are Seduced by the Sex Appeal of the Inorganic. Berkeley; Los Angeles; Londres: University of California, 1996.

HELLMAN, Mimi. Furniture, Sociability, and the Work of Leisure in Eighteenth-Century France. Eighteenth-Century Studies, v. 32, n. 4, p. 415-445, 1999.

HELLMAN, Mimi. Interior Motives: Seduction by Decoration in Eighteenth-Century France. In: KODA, H.; BOLTON, A. Dangerous Liaisons: Fashions and Furniture in the Eighteenth Century. Nova York; Londres: The Metropolitan Museum of Art; Yale University, 2004, p.15-23.

JODELET, Denise. Les representations sociales. In: MOSCOVICI, S. Psychologie sociale. Paris: Presses Universitaires, 1984, p. 358-378.

KIRKHAM, Pat (ed.). The Gendered Object. Manchester; Nova York: Manchester University, 1996.

KRAUS, Richard; HILSENDAGER, Sarah Chapman.; DIXON, Brenda. History of the Dance in Art and Education. Nova Jersey: Prentice-Hall, 1991.

LADURIE, Emmanuel Le Roy. Acontecimento e longa duração na história social: o exemplo dos chowans. In: NOVAIS, Fernando Antônio; SILVA, Rogério Forastieri da. Nova História em perspectiva. São Paulo: Cosac Naify, 2011, v. 1, p. 247-267.

LATOUR, Bruno. Reagregando o Social: uma introdução à teoria do ator-rede. Salvador; Bauru: EDUFBA; Edusc, 2012.

LIMA, Tania Andrade. Chá e Simpatia: uma Estratégia de Gênero no Rio de Janeiro Oitocentista. Anais do Museu Paulista. História e Cultura Material. Nova Série. v. 5, p. 93-129, jan./dez., 1997.

MENESES, Ulpiano Toledo Bezerra. O Objeto Material como Documento. Reprodução de aula ministrada no curso "Patrimônio Cultural: Políticas e Perspectivas", organizado pelo IAB/ Condephaat em 1980, ms, s.p.

MILLER, Daniel. Extracts from Material Culture and Mass Consumption. In: BUCHLI, Victor. Material Culture: Critical Concepts in the Social Sciences. Londres, Nova York: Routledge, 2004, v. II, p. 292-336. 
MILLER, Daniel. Materiality: an Introduction. In: MILLER, Daniel. Materiality. Durham; Londres: Duke University, 2005, p. 1-50.

MILLER, Leslie Shannon. The Many Figures of Eve: Styles of Womanhood Embodied in a LateNineteenth-Century Corset. In: PROWN, Jules Ddaved; HALTMAN, Kenneth. American Artifacts. Essays in Material Culture. East Lansing/Michigan: Michigan State University, 2000, p. 71-92.

MONTGOMERY, Maureen E. Displaying Women. Spectacles of Leisure in Edith Wharton's New York. Nova York: Rutledge, 1998.

OFFEN, Karen M.; PIERSON, Ruth Roach; RENDALL, Jane (eds.). Writing Women's History: International Perspectives. Londres; Bloomington: Indiana University, 1991.

POMIAN, Krzysztof. Colecção. Enciclopédia Einaudi. Lisboa: Imprensa Nacional-Casa da Moeda, 1984, v. 1, p. 51-86.

PORTINARI, Maribel. História da dança. Rio de Janeiro: Nova Fronteira, 1989.

SAHLINS, Marshall. Cultura e razão prática. Rio de Janeiro: Zahar, 1979.

SHARP, Katherine. Women's creativity and display in the eighteenth-century British domestic interior. In: McKELLER, Susie; SPARKE, Penny. Interior Design and Identity. Manchester: Manchester University, 2004, p. 10-26.

SOUZA, Gilda de Mello. O espírito das roupas: a moda no século XIX. São Paulo: Companhia das Letras, 1987.

STEWART, Susan. On Longing: Narratives of the Miniature, the Gigantic, the Souvenir, the Collection. Durham: Duke University, 1993.

UNRUH, Allison. Aspiring to la Vie Galante: Reincarnations of Rococo in Second Empire France. Tese (Doutorado) - Institute of Fine Arts, New York University. Nova York, 2008.

VEBLEN, Thorstein. Teoria da classe ociosa. São Paulo: Abril Cultural, 1983. MONTGOMERY, M. E. Displaying Women: spectacles of Leisure in Edith Wharton's New York. Londres ; Nova York: Routledge, 1998.

WILHELM, P.; REBER, H. La porcelaine européenne du XVIIIe. Siècle. Fribourg/Suisse: Office du Livre, 1980. 
A\&E Television Networks. History. 2019. This Day in History. February 15. Publicado em: 13 nov. 2009. Atualizado em: 27 jul. 2019. Disponível em: <https://bit.ly/2Wi3dhc>. Acesso em: 29 jun. 2015.

BOTAFOGO, Ana. Site oficial. Disponível em: <https://bit.ly/2BLL8ig $>$. Acesso em $1^{\circ}$ mar. 2016.

MDEMULHER. 2015. KIMURA, Gabriela. Lançamento: assista ao trailer do novo filme da Cinderela. Publicado em: 2 jan. 2015. Atualizado em: 27 out. 2016. Disponível em: <https:// bit.ly/32hXHNC>. Acesso em: 29 jun. 2015.

Artigo apresentado em 26/6/2019. Aprovado em 14/10/2019.

\section{(cc) BY}

All the contents of this journal, except where otherwise noted, is licensed under a Creative Commons Attribution License 